\title{
Graded Aerobic Treadmill Testing in Adolescent Traumatic Brain Injury Patients
}

\author{
Dean M. Cordingley, Richard Girardin, Marc P. Morissette, Karen Reimer, \\ Jeff Leiter, Kelly Russell, Michael J. Ellis
}

\begin{abstract}
Purpose: To examine the safety and tolerability of clinical graded aerobic treadmill testing in recovering adolescent moderate and severe traumatic brain injury (TBI) patients referred to a multidisciplinary pediatric concussion program. Methods: We completed a retrospective case series of two moderate and five severe TBI patients (mean age, 17.3 years) who underwent initial Buffalo Concussion Treadmill Testing at a mean time of 71.6 days (range, 55-87) postinjury. Results: Six patients completed one graded aerobic treadmill test each and one patient underwent initial and repeat testing. There were no complications. Five initial treadmill tests were completely tolerated and allowed an accurate assessment of exercise tolerance. Two initial tests were terminated early by the treatment team because of neurological and cardiorespiratory limitations. As a result of testing, two patients were cleared for aerobic exercise as tolerated and four patients were treated with individually tailored submaximal aerobic exercise programs resulting in subjective improvement in residual symptoms and/or exercise tolerance. Repeat treadmill testing in one patient performed after 1 month of treatment with submaximal aerobic exercise prescription was suggestive of improved exercise tolerance. One patient was able to tolerate aerobic exercise following surgery for posterior glottic stenosis. Conclusions: Preliminary results suggest that graded aerobic treadmill testing is a safe, well tolerated, and clinically useful tool to assess exercise tolerance in appropriately selected adolescent patients with TBI. Future prospective studies are needed to evaluate the effect of tailored submaximal aerobic exercise prescription on exercise tolerance and patient outcomes in recovering adolescent moderate and severe TBI patients.
\end{abstract}

RÉSUMÉ: Administrer à des adolescents victimes de lésions cérébrales traumatiques des épreuves graduelles d'effort sur tapis roulant. Objectif: Se pencher sur l'innocuité et sur la tolérance à des épreuves cliniques d'effort sur tapis roulant administrées, de façon graduelle, à des adolescents victimes de lésions cérébrales traumatiques (LCT) modérées et sévères qu'on a adressés, lors de leur période de convalescence, à un programme pédiatrique multidisciplinaire de prise en charge des commotions cérébrales. Méthodes: Nous avons mené une étude de série de cas rétrospective portant sur deux patients victimes de LCT modérées et sur sept patients victimes de LCT sévères (âge moyen : 17,3 ans) à qui l'on avait administré, en moyenne 71,6 jours (intervalle : 55-87) après leur accident, l'épreuve sur tapis roulant de Buffalo pour détecter des commotion cérébrales Résultats: Six patients ont complété chacun une épreuve graduelle d'effort sur tapis roulant ; un autre l'a effectué à deux reprises. Aucune complication n'est apparue. De ces six patients, cinq ont effectué l'épreuve en la tolérant complètement, ce qui a permis une évaluation précise. Fait à noter, deux patients qui en étaient à leur première épreuve ont dû la conclure de façon anticipée en raison de limitations neurologiques et cardio-respiratoires. À la suite de ces épreuves, deux patients ont obtenu l'autorisation d'effectuer des exercices d'aérobie, ces derniers étant désormais tolérés. Quatre patients ont été traités au moyen de programmes personnalisés d'exercices sous-maximaux, ce qui a entraîné une amélioration subjective de leurs symptômes résiduels et/ou de leur résistance à l'effort. Il est aussi apparu que le patient à qui l'on avait administré l'épreuve un mois après avoir subi des traitements, le limitant à des exercices d'aérobie sous-maximaux, donnait à voir une résistance à l'effort améliorée. Enfin, un patient a été en mesure d'endurer des exercices d'aérobie à la suite d'une chirurgie visant à traiter une sténose de la partie postérieure de la glotte. Conclusions: Des résultats préliminaires suggèrent que l'épreuve graduelle d'effort sur tapis roulant est un outil clinique sans risques, bien toléré et utile pour évaluer la résistance à l'effort dans le cas de patients adolescents victimes d'une LCT qui avaient été soigneusement sélectionnés. Des études prospectives ultérieures sont nécessaires pour évaluer les effets des programmes personnalisés d'exercices sous-maximaux quant à la résistance à l'effort et à l'évolution de l'état de santé de patients adolescents en convalescence après avoir été victimes de LCT modérées et sévères.

Keywords: adolescent, exercise intolerance, graded aerobic exercise testing, safety, traumatic brain injury

doi:10.1017/cjn.2017.209

Can J Neurol Sci. 2017; 44: 684-691

From the Pan Am Concussion Program (DMC, RG, MPM, K. Reimer, JL, MJE); Pan Am Clinic Foundation (DMC, RG, MPM, JL); Departments of Rehabilitation Sciences (K. Reimer); Surgery (JL, MJE); Pediatrics and Child Health (K. Russell, MJE); Section of Neurosurgery (MJE); University of Manitoba; Children's Hospital Research Institute of Manitoba (K. Russell, MJE); Canada North Concussion Network (DMC, RG, MPM, K. Reimer, JL, K. Russell, MJE), Winnipeg, Manitoba, Canada. Received January 19, 2017. Final Revisions Submitted April 12, 2017. Date of Acceptance April 24, 2017.

Correspondence to: Michael Ellis, Pan Am Clinic Foundation, 75 Poseidon Bay, Winnipeg, MB, Canada R3M 3E4. Email: mellis3@panamclinic.com 
Traumatic brain injury (TBI) is one of the leading causes of death and disability among children and adolescents worldwide. In the United States, it is estimated that pediatric TBI results in more than 630,000 emergency room visits, 60,000 hospital admissions, and 7,500 deaths annually. ${ }^{1}$ Sports and recreational activities account for a significant proportion of pediatric concussions and mild TBIs ${ }^{2-4}$; however, moderate and severe TBI in children and adolescents often result from other mechanisms such as motor vehicle collisions, falls, and nonaccidental trauma., Although the modern management of acute pediatric moderate and severe TBI is aimed at addressing the primary and secondary pathological aspects of this injury, ${ }^{6,7}$ the medical rehabilitation of surviving TBI patients requires a multidisciplinary, patient-centered approach to optimize functional recovery and patient outcomes.

In addition to motor, sensory, language, and cognitive impairments, ${ }^{8-12}$ patients with TBI can also develop significant aerobic deconditioning that is a product of numerous factors including functional deficits, associated injuries, and prolonged immobility. ${ }^{13,14}$ Previous studies have used a variety of exercise protocols to examine exercise tolerance in TBI patients, but these studies have been largely limited to adults who have undergone testing in the chronic stage of injury. These studies suggest that the aerobic capacity of adult TBI patients is reduced ${ }^{15-17}$ and that these patients demonstrate an impaired cardiorespiratory response to aerobic exercise. ${ }^{14-20}$ Despite these findings, there is no consensus on which exercise test or protocol is optimal for evaluating exercise tolerance in recovering adult or pediatric patients with moderate and severe TBI in the clinical setting. ${ }^{14}$

In contrast, graded aerobic treadmill testing has a wellestablished role in the evaluation and management of patients with concussion and persistent postconcussion syndrome. Evidence suggests that graded aerobic treadmill testing is a safe, welltolerated, and clinically useful tool that can be used to evaluate exercise tolerance and guide the development of individually tailored submaximal exercise programs in adult and pediatric concussion patients. $^{21-29}$ To date, however, there have been no studies that have examined the safety and tolerability of this clinical tool in recovering adolescent moderate and severe TBI patients.

Here, we present a retrospective case series of adolescent patients recovering from moderate and severe TBI who underwent graded aerobic treadmill testing at a multidisciplinary pediatric concussion program.

\section{MeTHODS}

\section{Ethics}

This retrospective study was approved by the institutional research ethics board at the University of Manitoba.

\section{Participants and Clinical Assessment}

A retrospective chart review was performed for all consecutive pediatric moderate and severe TBI patients who underwent graded aerobic treadmill testing at the Pan Am Concussion Program at Pan Am Clinic, Winnipeg, Manitoba, Canada. The Pan Am Concussion Program is a multidisciplinary pediatric concussion program that primarily provides outpatient consultation and rehabilitation services to pediatric patients (age 19 years and younger) with sports- and nonsports-related concussion and mild TBI throughout the province of Manitoba and neighboring regions.
The clinical team at the Pan Am Concussion Program comprises health care professionals with clinical training in TBI and neurorehabilitation such as experts in neurosurgery, neuropsychology, neurology, vestibular physiotherapy, exercise science, neuroophthalmology, and adolescent psychiatry. Therefore, the program occasionally receives referrals for pediatric patients recovering from moderate and severe TBI to aid in the optimization of out- and inpatient rehabilitation and guide return-to-learn and return-to-sports decision-making.

Accordingly, this study included patients who (1) were age 19 or younger, (2) were diagnosed with a moderate or severe TBI, and (3) underwent graded aerobic treadmill testing. Patients were not considered for graded aerobic treadmill testing if they were found to demonstrate motor, gait, or balance deficits that resulted in an inability to ambulate independently. Patients were also not considered for graded aerobic treadmill testing if they demonstrated language or cognitive deficits that resulted in an inability to provide informed consent or allow accurate rating of symptoms or perceived maximal exertion (RPE) during testing. In general, TBI patients were classified based on earliest reported Glasgow Coma Scale (GCS) score as moderate TBI patients (those with a GCS score of 9-12) and severe TBI patients (those with a GCS score of 8 or less). In cases were earliest reported GCS score was not documented in the medical records, TBI severity was based on the Mayo Clinic Classification for TBI severity, which includes other factors such as the presence of a loss of consciousness for 30 minutes or greater, posttraumatic amnesia for 24 hours or more, and the presence of traumatic abnormalities on neuroimaging. $^{30}$

All patients underwent initial clinical consultation at the pediatric concussion program carried out by a single neurosurgeon. Emergency medical service, initial emergency department, and inpatient hospital records as well as neuroimaging studies were reviewed. All patients underwent a clinical history and physical examination, including evaluation of cranial nerve, motor, sensory, cerebellar, gait, balance, vestibulo-ocular, and cervical spine functioning. Clinical data points that were extracted included patient age at injury, sex, mechanism of injury, earliest reported GCS score, TBI severity, neuroimaging findings, associated cranial and extracranial injuries, functional motor and balance deficits on physical examination, and treadmill testing results.

\section{Graded Aerobic Treadmill Testing}

The objectives of graded aerobic exercise testing in this cohort were to (1) evaluate patient exercise tolerance, (2) establish safe intensity parameters for future exercise, and (3) develop an individually tailored submaximal aerobic exercise program for those who exhibited a symptom-limited threshold or evidence of aerobic deconditioning during treadmill testing.

Before graded aerobic treadmill testing, all patients underwent medical clearance by the neurosurgeon using the Physical Activity and Readiness Medical Examination. ${ }^{31}$ Informed patient and parental consent was obtained before each test. Although previous research has shown that graded aerobic treadmill testing is safe and well tolerated in adolescent and adult concussion patients $^{21,26,29}$ as well as adult TBI patients, ${ }^{18,19,32}$ there are limited studies of graded aerobic treadmill testing in pediatric moderate and severe TBI patients. All patients and their parents were informed of the potential risks of testing, which included 
temporary worsening or exacerbation of neurological symptoms, falling off the treadmill and sustaining further injury, seizure, and shortness of breath, and muscle soreness related to exercise.

Following medical clearance and informed consent, all patients underwent Buffalo Concussion Treadmill Testing $(\mathrm{BCTT})^{24,26}$ performed by an experienced exercise physiologist and athletic therapist under the supervision of the neurosurgeon. All tests were performed by the same exercise physiologist and neurosurgeon. During testing, all subjects wore a Zephyr BioHarness (Zephyr Technology, Annapolis, MD) affixed to their chest that allowed continuous monitoring of heart rate (HR) throughout the test. Using a modified Balke protocol, patients performed an incremental exercise protocol until a symptomlimited threshold or maximal exhaustion was achieved (defined as an RPE of 18-20 on the Borg scale). ${ }^{33}$ Previous studies using the BCTT have defined a symptom-limited threshold as a $\geq 3$-point change in symptom report on a standardized Likert scale at any point during the test when compared with the patient's pretest symptom level. ${ }^{26,29}$ However, for use in this unique patient population, we chose to define a symptom-limited threshold as a $\geq 2$-point change in symptom report compared with the patient's pretest symptom level. Suggested starting speeds for the BCTT in concussion patients vary in the literature from 3.0 to 3.6 miles per hour (mph) and can be modified according to the patient's size and fitness level. ${ }^{26,29,34}$ For pediatric moderate and severe TBI patients, a starting speed of $3.2 \mathrm{mph}$ was used but was modified on an individual basis depending on patient comfort. For each study, the test began with the patient walking at $0 \%$ grade for the first minute, after which the grade was increased by $1 \%$ per minute for the first 15 minutes. After 15 minutes, the speed was increased $0.2 \mathrm{mph} / \mathrm{minute}$. Patients were asked to rate their symptoms and RPE every minute. Clinical reasons for test termination and complications of treadmill testing were also recorded. Total testing duration as well as maximal $\mathrm{HR}$ and blood pressure were collected following termination of treadmill testing. Age-predicted maximal HR was calculated using the equation (220 - patient's age) and the HR measured at the time of test termination was used to calculate the percentage of age-predicted maximal $\mathrm{HR}$ achieved. Predicted $\mathrm{VO}_{2}$ peak was calculated using the American College of Sport Medicine walking equation. ${ }^{35}$

\section{Clinical Management and Follow-Up}

Based on clinical presentation and testing results, selected patients were prescribed a tailored submaximal exercise program starting at 3 days and increasing to 5 days a week, which consisted of a 5-minute warm-up, 20 minutes of aerobic exercise at $80 \%$ of the maximum HR achieved during treadmill testing (or equivalent RPE), and a 5-minute cool down period. For patients who were receiving inpatient rehabilitation, patients were advised to perform the tailored submaximal aerobic exercise program under the supervision of a licensed heath care professional (i.e. physiotherapist). For those not receiving inpatient rehabilitation, patients were advised to perform the tailored submaximal aerobic exercise program under the supervision of a parent. Patient compliance with the submaximal exercise prescription was monitored through clinical follow-up and not formally with logbooks or digital watches. Follow-up appointments and repeat treadmill testing were scheduled as indicated by the treatment team and not according to a predesigned research protocol. Other targeted

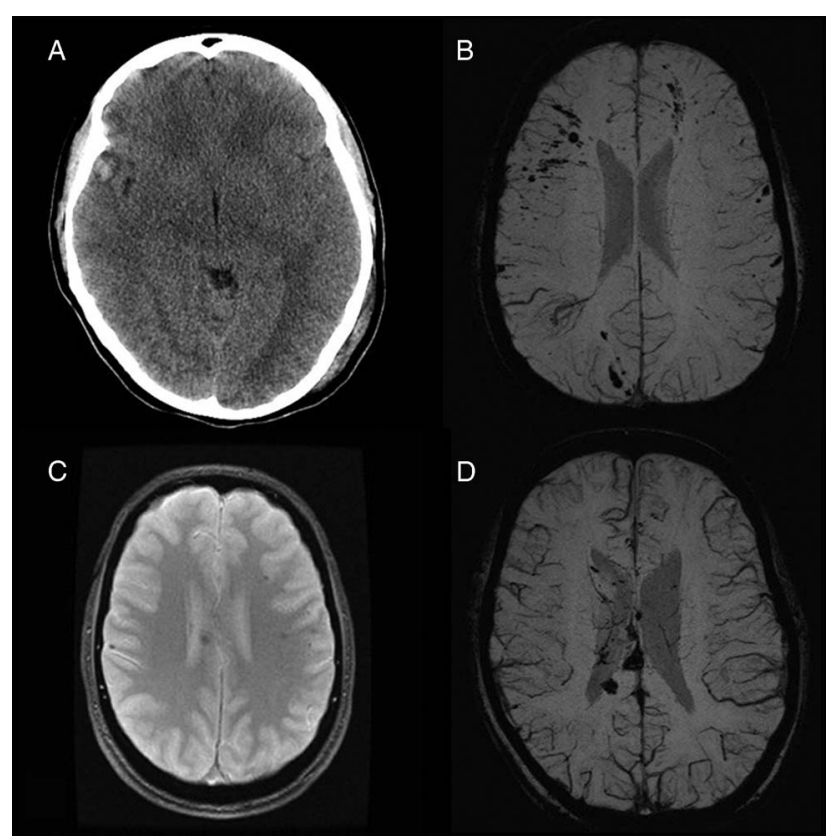

Figure 1: Representative neuroimaging findings among pediatric moderate and severe TBI patients who underwent graded aerobic treadmill testing. (A) Axial computed tomography scan in a 17-year-old female moderate TBI patient demonstrates a right temporal contusion (patient 3). (B) Axial susceptibility-weighted magnetic resonance imaging (MRI) scan in a 17-year-old female severe TBI patient demonstrates multifocal cortical and subcortical microhemorrhages consistent with diffuse axonal injury (patient 2). (C) Axial gradient recalled echo MRI in a 19-year-old male severe TBI patient demonstrates multiple hemorrhages within the corpus callosum and white matter consistent with diffuse axonal injury (patient 5). (D) Axial susceptibility-weighted MRI in an 18-year-old female severe TBI patient demonstrates multifocal microhemorrhages within the corpus callosum and white matter consistent with diffuse axonal injury (patient 6).

rehabilitative interventions were initiated as clinically indicated by the multidisciplinary concussion program team.

\section{Statistical Analysis}

The distributions of baseline characteristics for TBI patients who underwent graded aerobic treadmill testing were summarized using proportions for dichotomous and polytomous characteristics and means with standard deviations or ranges for continuous characteristics. Treadmill testing results and patient outcomes were tabulated.

\section{Results}

\section{Study Participants}

From October 22, 2014, to March 21, 2017, eight adolescent moderate or severe TBI patients were referred to the multidisciplinary pediatric concussion program. Seven patients were offered and agreed to undergo graded aerobic treadmill testing as part of their clinical management. The remaining patient was considered for graded aerobic treadmill testing, but was lost to follow-up before testing could be completed. Overall, the cohort included five females and two males with a mean age of 17.3 years (range, 16-19 years). Mechanisms of injury sustained by these patients included passengerrestrained motor vehicle collision $(n=5)$, passenger-nonrestrained 
motor vehicle collision $(\mathrm{n}=1)$, and a fall from the third story of a building $(n=1)$. Based on earliest reported GCS, one patient was classified as a moderate TBI patient and five were classified as severe TBI patients. Earliest reported GCS was not documented for one patient who was classified as a moderate TBI patient based on clinical history (40-minute loss of consciousness) and neuroimaging findings. Neuroimaging studies demonstrated evidence of structural brain injury in all patients (Figure 1). The most frequent neuroimaging findings were diffuse axonal injury $(\mathrm{n}=5)$, traumatic subarachnoid hemorrhage $(n=3)$, intracerebral contusion $(n=3)$, and acute subdural hematoma $(n=3)$. Associated cranial injuries included petrous temporal bone fracture with conductive hearing impairment $(n=1)$, occipital calvarial skull fracture and petrous temporal bone fracture with sensorineural hearing impairment and posttraumatic benign paroxysmal positional vertigo $(n=1)$, stable occipital condyle fracture $(n=1)$, complex maxillofacial and mandibular fractures requiring surgical reconstruction and tracheostomy $(n=1)$, and frontal calvarial skull fracture and indirect traumatic optic neuropathy $(n=1)$. Extracranial injuries among these patients included stable $\mathrm{C} 1$ vertebral fracture $(n=1)$, subaxial cervical spine ligamentous injury, T4 vertebral transverse process fracture, spleen laceration $(n=1)$, and nonoperative mesenteric root injury and pulmonary contusion $(n=1)$. Based on physical examination findings, two patients were found to demonstrate subtle right-sided hemiparesis and incoordination, whereas five demonstrated mild impairments on balance testing. For additional features of the study cohort, see Table 1 . The one patient diagnosed with posttraumatic benign paroxysmal positional vertigo underwent comprehensive evaluation by a vestibular physiotherapist and successful treatment with canalith repositioning before initial graded aerobic treadmill testing.

\section{Safety and Tolerability of Graded Aerobic Treadmill Testing}

In this study, six adolescent TBI patients completed a single graded aerobic treadmill test and one patient underwent two tests. The mean time from injury to initial treadmill testing for the entire cohort was 71.6 days (range, 55-87 days).

There were no complications related to treadmill testing among this cohort. The mean duration of all treadmill tests was 19.5 minutes (range, 12-27 minutes). Overall, 6/8 (75\%) tests were well tolerated and allowed an accurate assessment of exercise tolerance. During initial treadmill testing, four patients terminated the test because of volitional exhaustion and one patient achieved a symptom-limited threshold during testing. In two patients, testing was terminated by the treatment team. One test was terminated for precautionary reasons because of patient ataxia and imbalance during light jogging after 22 minutes of exercise at an RPE of 17 (i.e. near maximal exhaustion). Another test was terminated early because of the development of mild inspiratory and expiratory stridor after 14 minutes of exercise. The mean maximum HR achieved during initial treadmill testing was 180 bpm (range, 139-205) resulting in a mean percentage-predicted maximum HR of $88.9 \%$ (range, $68.5 \%-100.5 \%$ ) achieved during testing for the entire cohort. The percentage-predicted maximal HR achieved among patients who terminated the test because of fatigue ranged from $83.3 \%$ to $100.0 \%$. The one patient who experienced a symptom-limiting threshold during testing achieved $68.5 \%$ of their age-predicted maximal HR. Although one test was terminated because of ataxia and imbalance, the patient achieved $100 \%$ of her age-predicted maximal HR. The patient whose test was terminated for stridor achieved $95 \%$ of her agepredicted maximal HR; however, it was unclear to what extent an increased work of breathing may have contributed to an increase in HR. The mean predicted $\mathrm{VO}_{2}$ peak for this cohort during initial treadmill testing was 37.5 (range, $29.1-43 \mathrm{ml} / \mathrm{kg}^{-1} / \mathrm{min}^{-1}$ ).

As a result of graded aerobic treadmill testing, two patients were cleared to participate in aerobic exercise as tolerated. Four patients were treated with an individually tailored submaximal exercise prescription resulting in subjective improvement in residual symptoms (i.e. headaches, fatigue) and/or exercise tolerance on follow-up interview (Table 1). One patient treated with an individually tailored submaximal aerobic exercise program underwent repeat treadmill testing using the same test parameters and demonstrated results suggestive of improved exercise tolerance including longer test duration and higher maximum $\mathrm{HR}$ and $\mathrm{VO}_{2}$ peak achieved during testing. The patient whose treadmill test was terminated because of mild stridor was referred to an ear, nose, and throat surgeon, leading to a diagnosis of posterior glottic stenosis that was likely secondary to intubation during the patient's initial hospital admission. This patient had been discharged from an inpatient rehabilitation hospital and had returned to exercise before undergoing graded aerobic treadmill testing. This condition was treated surgically resulting in complete resolution of the exercise-induced stridor. In clinical follow-up, the patient was able to resume aerobic exercise without any limitation or postconcussion symptoms.

\section{Discussion}

The results of this study provide preliminary evidence that graded aerobic treadmill testing is a safe, well-tolerated, and clinically useful tool to evaluate exercise tolerance in carefully selected adolescent moderate and severe TBI patients.

Exercise tolerance and aerobic capacity can be estimated in the clinical and laboratory setting by measuring cardiorespiratory function while a patient or subject is exposed to an incremental increase in aerobic exercise. Standardized tests used in TBI patients have included timed walking tests and treadmill- or exercise bike-based protocols ${ }^{15,16,18,19,32,36-38}$; however there is no accepted clinical standard for evaluating exercise tolerance in this patient population. ${ }^{14}$ Over the past 5 to 10 years, standardized graded aerobic treadmill testing has emerged as a safe, welltolerated, and clinically useful tool that can be used to evaluate exercise tolerance in adult and pediatric concussion patients. ${ }^{21,22,24-29}$

Previous research has shown that the BCTT demonstrates good test-retest reliability for evaluation of symptom-limiting HR in concussion patients with poorer reliability observed among other variables such as maximal systolic and diastolic blood pressure measurements and maximum reported perceived exertion. Importantly, the test demonstrates a sensitivity of $99 \%$ for identifying subjects with a symptom-limited threshold and a specificity of $89 \%$ for ruling out concussion symptoms with high interrater reliability $(95 \%)$ for test interpretation across a variety of professionals. $^{26}$ To date, however, the authors are not aware of any studies that have examined graded aerobic exercise testing among an exclusive cohort of adolescent moderate and severe TBI patients. In this study, there were no serious complications or adverse events among the adolescent moderate and severe TBI patients who underwent graded aerobic treadmill testing. Six of 


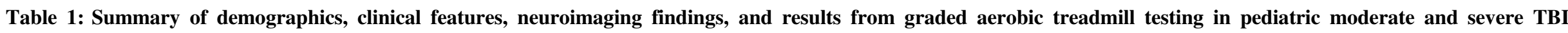
patients.

\begin{tabular}{|c|c|c|c|c|c|c|c|c|c|c|c|c|}
\hline $\begin{array}{l}\text { Patient } \\
\text { number }\end{array}$ & $\begin{array}{l}\text { Age/ } \\
\text { sex }\end{array}$ & $\begin{array}{l}\text { Injury } \\
\text { mechanism }\end{array}$ & $\begin{array}{l}\text { GCS/TBI } \\
\text { severity/clinical } \\
\text { deficits }\end{array}$ & $\begin{array}{l}\text { Neuroima- } \\
\text { ging findings }\end{array}$ & $\begin{array}{l}\text { Associated injuries/ } \\
\text { comorbidities }\end{array}$ & $\begin{array}{l}\text { Time from } \\
\text { injury to } \\
\text { testing }\end{array}$ & $\begin{array}{c}\text { Duration of } \\
\text { treadmill test } \\
\text { (minutes) }\end{array}$ & Complications & $\begin{array}{l}\text { Maximum } \\
\mathrm{HR} / \text { reason } \\
\text { for test } \\
\text { termination } \\
\end{array}$ & $\begin{array}{c}\% \text { of age- } \\
\text { predicted } \\
\text { maximum } \\
\text { HR } \\
\end{array}$ & $\begin{array}{c}\text { Predicted } \\
\mathrm{VO}_{2} \text { peak }(\mathrm{ml} / \\
\left.\mathrm{kg}^{-1} / \mathrm{min}^{-1}\right)\end{array}$ & $\begin{array}{l}\text { Outcome (duration } \\
\text { of follow-up after } \\
\text { testing) }\end{array}$ \\
\hline 1 & $16 \mathrm{M}$ & $\begin{array}{l}\text { Passenger } \\
\text { nonrestrained } \\
\text { MVC }\end{array}$ & $\begin{array}{ll}3 & \\
& \text { Severe } \\
& \text { Postural } \\
\text { imbalance }\end{array}$ & $\begin{array}{l}\text { aSDH, tSAH, } \\
\text { calvarial } \\
\text { temporal } \\
\text { bone } \\
\text { fracture } \\
\end{array}$ & $\begin{array}{l}\text { None } \\
\text { Conductive } \\
\text { hearing } \\
\text { impairment }\end{array}$ & 83 days & 22 & None & $\begin{array}{c}205 \mathrm{bpm} \\
\text { Fatigue }\end{array}$ & 100.5 & 43.00 & $\begin{array}{l}\text { Cleared for aerobic } \\
\text { exercise as tolerated } \\
\text { (NA) }\end{array}$ \\
\hline 2 & $17 \mathrm{~F}$ & $\begin{array}{l}\text { Passenger } \\
\text { restrained } \\
\text { MVC }\end{array}$ & $\begin{array}{l}9 \\
\text { Moderate } \\
\text { None }\end{array}$ & $\begin{array}{l}\text { IPC, DAI, } \\
\text { occipital } \\
\text { condyle } \\
\text { fracture }\end{array}$ & $\begin{array}{l}\text { Posterior glottic } \\
\text { stenosis }\end{array}$ & 55 days & 14 & None & $\begin{array}{l}193 \text { bpm } \\
\text { Inspiratory/ } \\
\text { expiratory } \\
\text { stridor }\end{array}$ & 95.1 & 32.14 & $\begin{array}{l}\text { Improved exercise } \\
\text { tolerance following } \\
\text { surgery for } \\
\text { posterior glottis } \\
\text { stenosis } \\
\text { (133 days) }\end{array}$ \\
\hline 3 & $17 \mathrm{~F}$ & $\begin{array}{l}\text { Passenger } \\
\text { restrained } \\
\text { MVC }\end{array}$ & $\begin{array}{l}\text { NA } \\
\quad \text { Moderate } \\
\text { Postural } \\
\text { imbalance }\end{array}$ & $\begin{array}{l}\text { IPC, petrous } \\
\text { temporal } \\
\text { and } \\
\text { occipital } \\
\text { skull } \\
\text { fractures } \\
\end{array}$ & $\begin{array}{l}\text { BPPV and } \\
\text { sensorineural } \\
\text { hearing } \\
\text { impairment }\end{array}$ & 77 days & 12 & None & $\begin{array}{l}139 \text { bpm } \\
\text { Symptom- } \\
\text { limited } \\
\text { threshold }\end{array}$ & 68.5 & 29.06 & $\begin{array}{l}\text { Clinical improvement } \\
\text { with submaximal } \\
\text { exercise } \\
\text { prescription } \\
\text { (181 days) }\end{array}$ \\
\hline 4 & $17 \mathrm{~F}$ & $\begin{array}{l}\text { Passenger } \\
\text { restrained } \\
\text { MVC }\end{array}$ & $\begin{array}{l}7 \\
\text { Severe } \\
\text { None }\end{array}$ & DAI & $\begin{array}{l}\text { Extensive facial } \\
\text { fractures requiring } \\
\text { reconstruction and } \\
\text { temporary } \\
\text { tracheostomy; } \\
\text { stable } \mathrm{C} 1 \text { fracture }\end{array}$ & 68 days & 19 & None & $\begin{array}{l}171 \mathrm{bpm} \\
\text { Fatigue }\end{array}$ & 84.2 & 39.20 & $\begin{array}{l}\text { Clinical improvement } \\
\text { with submaximal } \\
\text { exercise } \\
\text { prescription } \\
\text { (15 days) }\end{array}$ \\
\hline 5 & $19 \mathrm{M}$ & $\begin{array}{l}\text { Fall from third } \\
\text { story of } \\
\text { building }\end{array}$ & $\begin{array}{ll}5 & \\
& \text { Severe } \\
\text { Right-sided } \\
\text { weakness and } \\
\text { incoordination } \\
\text { and postural } \\
\text { imbalance } \\
\end{array}$ & $\begin{array}{l}\text { aSDH, tSAH, } \\
\text { IVH, DAI }\end{array}$ & $\begin{array}{l}\text { Splenic laceration, } \\
\text { subaxial cervical } \\
\text { spine ligamentous } \\
\text { injury, T4 } \\
\text { transverse process } \\
\text { fracture }\end{array}$ & 87 days & 19 & None & $\begin{array}{c}180 \mathrm{bpm} \\
\text { Fatigue }\end{array}$ & 90.5 & 41.18 & $\begin{array}{l}\text { Clinical improvement } \\
\text { with submaximal } \\
\text { exercise } \\
\text { prescription } \\
\text { (22 days) }\end{array}$ \\
\hline 6 & $18 \mathrm{~F}$ & $\begin{array}{l}\text { Passenger } \\
\text { restrained } \\
\text { MVC }\end{array}$ & $\begin{array}{ll}5 & \\
& \text { Severe } \\
& \text { Right-sided } \\
\text { weakness and } \\
\text { incoordination } \\
\text { and postural } \\
\text { imbalance } \\
\end{array}$ & $\begin{array}{l}\text { tSAH, IVH, } \\
\text { DAI }\end{array}$ & $\begin{array}{l}\text { Mesenteric root } \\
\text { injury, pulmonary } \\
\text { contusion }\end{array}$ & 62 days & 22 & None & $\begin{array}{l}202 \mathrm{bpm} \\
\text { Ataxia and } \\
\text { imbalance }\end{array}$ & 100 & 43.00 & $\begin{array}{l}\text { Cleared for aerobic } \\
\text { exercise as tolerated } \\
\text { (NA) }\end{array}$ \\
\hline 7 & $17 \mathrm{~F}$ & $\begin{array}{l}\text { Passenger } \\
\text { restrained } \\
\text { MVC }\end{array}$ & $\begin{array}{ll}5 & \\
& \text { Severe } \\
& \text { Postural } \\
\text { imbalance }\end{array}$ & $\begin{array}{l}\text { EDH, SDH, } \\
\text { DAI, IPC, } \\
\text { frontal } \\
\text { calvarial } \\
\text { skull } \\
\text { fracture }\end{array}$ & $\begin{array}{l}\text { Traumatic optic } \\
\text { neuropathy and } \\
\text { visual field defect }\end{array}$ & $\begin{array}{l}\text { Initial test: } \\
69 \text { days } \\
\text { Follow-up } \\
\text { test: } 90 \text { days }\end{array}$ & $\begin{array}{l}21 \\
27\end{array}$ & $\begin{array}{l}\text { None } \\
\text { None }\end{array}$ & $\begin{array}{c}169 \mathrm{bpm} \\
\text { Fatigue } \\
80 \mathrm{bpm} \\
\text { Fatigue }\end{array}$ & $\begin{array}{l}83.3 \% \\
88.7 \%\end{array}$ & 45.00 & $\begin{array}{l}\text { Clinical improvement } \\
\text { with submaximal } \\
\text { exercise } \\
\text { prescription } \\
\text { Repeat treadmill } \\
\text { testing suggestive } \\
\text { of improved } \\
\text { exercise tolerance } \\
\text { (118 days) }\end{array}$ \\
\hline
\end{tabular}

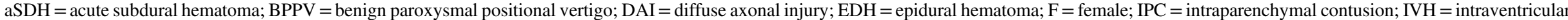
hemorrhage; $\mathrm{M}=$ male; $\mathrm{MVC}=$ motor vehicle collision; $\mathrm{NA}=$ not available; $\mathrm{tSAH}=$ traumatic subarachnoid hemorrhage. 
the eight tests were completed and allowed an accurate assessment of exercise tolerance. Although it is important for all pediatric concussion and TBI patients to undergo medical screening by a physician before graded aerobic treadmill testing, this is especially important in pediatric moderate and severe TBI patients who may have motor, sensory, cognitive, or balance impairments that can affect the safety of exercise testing. Furthermore, TBI patients can also harbor coexisting orthopedic, vascular, pulmonary, or hematological conditions that may also limit exercise capacity. ${ }^{39-43}$ In this study, two treadmill tests were terminated by the treatment team. One test was terminated late in the study because of patient ataxia and imbalance secondary to previously known right-sided weakness. In another case, treadmill testing was terminated early because of onset of mild inspiratory and expiratory stridor resulting in early detection and management of previously unknown posterior subglottic stenosis. Taken together, these findings suggest that graded aerobic treadmill testing is safe and well tolerated in selected adolescent patients with moderate and severe TBI, but requires rigorous medical screening performed by a physician with clinical training in TBI and trauma and careful patient monitoring during testing by an experienced exercise physiologist.

Using a variety of exercise testing protocols, previous studies have demonstrated impairments in exercise tolerance and aerobic capacity as well as alterations in the cardiorespiratory response to maximal and submaximal exercise among TBI patients. It is estimated that the peak aerobic capacity is reduced to $65 \%$ to $74 \%$ of normal among adult TBI patients. ${ }^{15-17}$ These patients also exhibit lower peak responses in HR, oxygen pulse, oxygen consumption, minute ventilation during exercise, and lower ventilatory anaerobic thresholds. ${ }^{14-19}$ One study performed graded treadmill testing in a sample of adult TBI patients a mean of 10.4 months postinjury and found that only $61.5 \%$ of patients were able to reach greater than $90 \%$ of their age-predicted maximal HR during treadmill testing. ${ }^{19}$ The level of aerobic deconditioning and exercise intolerance observed among TBI patients is highly variable and is likely dependent on a number of factors, including patient age, preinjury fitness levels, TBI severity, associated neurological and extracranial injuries that limit mobility, length of initial hospitalization and immobility, the degree to which aerobic exercise is incorporated into postinjury rehabilitation, and the time at which the patient undergoes exercise testing relative to the date of injury. To date, most of the studies examining exercise tolerance in TBI patients have been limited to adults with moderate and severe injuries who have undergone testing on average 10 months to years after injury. ${ }^{14-19}$ In this study of exclusive adolescent patients with predominantly severe TBI assessed less than 3 months postinjury, we found surprisingly good aerobic exercise tolerance in most patients. Although we did not perform comprehensive assessment of cardiorespiratory physiology, all patients were capable of exercising for periods that were similar to those achieved by adult and pediatric concussion patients during treadmill testing, ${ }^{21,24,28}$ and four of the seven patients reached greater than $90 \%$ of their age-predicted maximal HR. However, predicted $\mathrm{VO}_{2}$ peak values were below those reported in healthy adolescents, ${ }^{44}$ suggesting that there is a level of deconditioning in adolescent patients with moderate and severe TBI.

In concussion patients with clinical evidence of aerobic exercise intolerance (i.e. autonomic/physiological postconcussion disorder), emerging evidence suggests that tailored aerobic exercise may be an effective treatment option to reduce concussion symptoms and enhance clinical and physiological recovery. Laboratory studies suggest that exercise may promote TBI recovery through the anti-inflammatory, neuroprotective, and neuroplastic effects of proteins such as brain-derived neurotrophic factor as well as through restoration of autonomic nervous system and cerebrovascular function. ${ }^{25,45-47}$ In adult and pediatric concussion patients, the results of graded aerobic treadmill testing can be used to design individually tailored submaximal exercise programs. Studies suggest that submaximal exercise prescription leads to a high rate of symptomatic improvement and return to full functioning in adult and pediatric autonomic/physiological postconcussion disorder patients $(70 \%-90 \%) .^{21,25,28,48}$ Preliminary research also suggests that these clinical improvements correlate with improvements in objective measures of physiological recovery including exercise tolerance, cerebral blood flow, and cerebrovascular reactivity. ${ }^{49,50}$ Although some studies have demonstrated significant improvements in exercise capacity and peak cardiorespiratory responses among adult moderate and severe TBI patients treated with aerobic exercise programs, ${ }^{13,17,51,52}$ there has been limited focus on this therapeutic intervention in adolescent patients with TBI. Based on the results of graded aerobic treadmill testing, four patients in this study were prescribed individually tailored submaximal aerobic exercise programs. Although repeat testing was not uniformly undertaken to confirm improvements in exercise tolerance, all patients reported an improvement in residual symptoms and/or exercise tolerance following submaximal aerobic exercise prescription. Repeat treadmill testing in one patient performed 1 month after treatment with an individually tailored submaximal aerobic exercise program was suggestive of improved exercise tolerance as reflected by a longer test duration and higher maximum HR and $\mathrm{VO}_{2}$ peak achieved during testing.

The present pilot study has several limitations. First, the sample size is small and was limited to older adolescents. Second, this study was carried out at a multidisciplinary pediatric concussion program that likely selected for moderate and severe TBI patients who had achieved a good functional outcome postinjury and may not be representative of a more generalized pediatric moderate and severe TBI population. Third, patients did not go undergo comprehensive physiological monitoring of cardiorespiratory function during treadmill testing. Fourth, although all study participants were active adolescents prior to injury, baseline exercise tolerance and fitness level data were not available for comparison to postinjury graded aerobic treadmill testing results. Fifth, compliance with submaximal aerobic exercise programs was not rigorously monitored with digital watches or logbooks and repeat graded aerobic treadmill testing was not performed in the majority of patients. Sixth, this study did not include a control group. Taken together, these factors limit conclusions regarding the independent effect of exercise on patient symptoms and exercise tolerance but highlight factors that should be considered in future prospective studies. Future work is also needed to examine the interrater and test-retest reliability of graded aerobic treadmill testing in this unique TBI population.

In conclusion, preliminary results from this pilot study suggest that graded aerobic treadmill testing is safe, well tolerated, and can be used to evaluate exercise tolerance in appropriately selected adolescent moderate and severe TBI patients. Optimizing the use of graded aerobic treadmill testing requires a multidisciplinary team 
with clinical training and experience in TBI, trauma, and exercise physiology who can facilitate comprehensive patient screening and monitoring for neurological and cardiorespiratory factors that may limit exercise tolerance. Although standardized BCTT is commonly used in the management of pediatric concussion patients, modifications to the starting speed and test termination symptom threshold should be considered when applying this technique to adolescent moderate and severe TBI patients. Despite the encouraging preliminary results presented here, future studies are needed to confirm the safety and tolerability of graded aerobic treadmill testing in a larger sample of TBI patients including younger adolescents and children. Longitudinal studies using continuous monitoring of cardiovascular, autonomic, and respiratory functioning as well as cerebral blood flow during exercise testing are also needed to understand the pathophysiological mechanisms that mediate aerobic exercise intolerance following pediatric TBI.

\section{ACKNOWLEDGMENTS}

All phases of this study were supported by a grant from the Pan Am Clinic Foundation, Winnipeg Jets True North Foundation and a generous donation by Leonard and Susan Asper.

DMC, RG, JL, MPM, K. Reimer, K. Russell, and MJE report grants from Pan Am Clinic Foundation, grants from Winnipeg Jets True North Foundation, and grants from Donation to Pan Am Clinic Foundation by Leonard and Susan Asper, during the conduct of the study.

\section{StATEMENT OF AUTHORShIP}

DMC, JL, K. Russell, and MJE conceptualized and designed the study, carried out the data collection and analysis, drafted the initial manuscript, critically reviewed and revised the manuscript, and approved the final manuscript as submitted. RG, MPM, and K. Reimer carried out data collection and analysis, critically reviewed and revised the manuscript, and approved the final manuscript as submitted. All authors approved the final manuscript as submitted and agree to be accountable for all aspects of the work.

\section{REFERENCES}

1. Thurman DJ. The epidemiology of traumatic brain injury in children and youths: a review of research since 1990. J Child Neurol. 2016;31:20-7.

2. Cusimano MD, Cho N, Amin K, et al. Mechanisms of team-sportrelated brain injuries in children 5 to 19 years old: opportunities for prevention. PLoS One. 2013;8:e58868.

3. Meehan WP, 3rd, Mannix R. Pediatric concussions in United States emergency departments in the years 2002 to 2006. J Pediatr. 2010;157:889-93.

4. Zemek R, Barrowman N, Freedman SB, et al. Clinical risk score for persistent postconcussion symptoms among children with acute concussion in the ED. JAMA. 2016;315:1014-25.

5. Dewan MC, Mummareddy N, Wellons JC, 3rd, Bonfield CM. The epidemiology of global pediatric traumatic brain injury: a qualitative review. World Neurosurg. 2016;91:497-509.

6. Kochanek PM, Carney N, Adelson PD, et al. Guidelines for the acute medical management of severe traumatic brain injury in infants, children, and adolescents-second edition. Pediatr Crit Care Med. 2012;13(Suppl 1):S1-82.

7. Scaife ER, Statler KD. Traumatic brain injury: preferred methods and targets for resuscitation. Curr Opin Pediatr. 2010;22:339-45.

8. Anderson V, Godfrey C, Rosenfeld JV, Catroppa C. Predictors of cognitive function and recovery 10 years after traumatic brain injury in young children. Pediatrics. 2012;129:e254-61.
9. Anderson VA, Morse SA, Catroppa C, Haritou F, Rosenfeld JV. Thirty month outcome from early childhood head injury: a prospective analysis of neurobehavioural recovery. Brain. 2004;127: 2608-2620.

10. Babikian T, Asarnow R. Neurocognitive outcomes and recovery after pediatric TBI: meta-analytic review of the literature. Neuropsychology. 2009;23:283-96.

11. Kuhtz-Buschbeck JP, Hoppe B, Golge M, Dreesmann M, Damm-Stunitz U, Ritz A. Sensorimotor recovery in children after traumatic brain injury: analyses of gait, gross motor, and fine motor skills. Dev Med Child Neurol. 2003;45:821-8.

12. Walker WC, Pickett TC. Motor impairment after severe traumatic brain injury: a longitudinal multicenter study. J Rehabil Res Dev. 2007;44:975-82.

13. Bateman A, Culpan FJ, Pickering AD, Powell JH, Scott OM, Greenwood RJ. The effect of aerobic training on rehabilitation outcomes after recent severe brain injury: a randomized controlled evaluation. Arch Phys Med Rehabil. 2001;82:174-82.

14. Mossberg KA, Amonette WE, Masel BE. Endurance training and cardiorespiratory conditioning after traumatic brain injury. J Head Trauma Rehabil. 2010;25:173-83.

15. Bhambhani Y, Rowland G, Farag M. Reliability of peak cardiorespiratory responses in patients with moderate to severe traumatic brain injury. Arch Phys Med Rehabil. 2003;84:1629-36.

16. Hunter M, Tomberlin J, Kirkikis C, Kuna ST. Progressive exercise testing in closed head-injured subjects: comparison of exercise apparatus in assessment of a physical conditioning program. Phys Ther. 1990;70:363-71.

17. Jankowski LW, Sullivan SJ. Aerobic and neuromuscular training: effect on the capacity, efficiency, and fatigability of patients with traumatic brain injuries. Arch Phys Med Rehabil. 1990;71:500-4.

18. Amonette WE, Mossberg KA. Ventilatory anaerobic thresholds of individuals recovering from traumatic brain injury compared with noninjured controls. J Head Trauma Rehabil. 2013;28:E13-20.

19. Mossberg KA, Ayala D, Baker T, Heard J, Masel B. Aerobic capacity after traumatic brain injury: comparison with a nondisabled cohort. Arch Phys Med Rehabil. 2007;88:315-20.

20. Mossberg KA, Orlander EE, Norcross JL. Cardiorespiratory capacity after weight-supported treadmill training in patients with traumatic brain injury. Phys Ther. 2008;88:77-87.

21. Cordingley D, Girardin R, Reimer K, et al. Graded aerobic treadmill testing in pediatric sports-related concussion: safety, clinical use, and patient outcomes. J Neurosurg Pediatr. 2016;25:693-702.

22. Darling SR, Leddy JJ, Baker JG, et al. Evaluation of the Zurich Guidelines and exercise testing for return to play in adolescents following concussion. Clin J Sport Med. 2014;24:128-33.

23. Ellis MJ, Leddy JJ, Willer B. Physiological, vestibulo-ocular and cervicogenic post-concussion disorders: an evidence-based classification system with directions for treatment. Brain Inj. 2014;29:1-11.

24. Kozlowski KF, Graham J, Leddy JJ, Devinney-Boymel L, Willer BS. Exercise intolerance in individuals with postconcussion syndrome. J Athl Train. 2013;48:627-35.

25. Leddy J, Hinds A, Sirica D, Willer B. The role of controlled exercise in concussion management. PM R. 2016;8:S91-100.

26. Leddy JJ, Baker JG, Kozlowski K, Bisson L, Willer B. Reliability of a graded exercise test for assessing recovery from concussion. Clin J Sport Med. 2011;21:89-94.

27. Leddy JJ, Baker JG, Merchant A, et al. Brain or strain? Symptoms alone do not distinguish physiologic concussion from cervical/ vestibular injury. Clin J Sport Med. 2015;25:237-42.

28. Leddy JJ, Kozlowski K, Donnelly JP, Pendergast DR, Epstein LH, Willer B. A preliminary study of subsymptom threshold exercise training for refractory post-concussion syndrome. Clin J Sport Med. 2010;20:21-7.

29. Leddy JJ, Willer B. Use of graded exercise testing in concussion and return-to-activity management. Curr Sports Med Re. p2013;12:370-6.

30. Malec JF, Brown AW, Leibson CL, et al. The mayo classification system for traumatic brain injury severity. J Neurotrauma. 2007;24:1417-24.

31. Jamnik VK, Warburton DE, Makarski J, et al. Enhancing the effectiveness of clearance for physical activity participation: background and overall process. Appl Physiol Nutr Metab. 2011;36(Suppl 1):S3-13. 
32. Mossberg KA, Greene BP. Reliability of graded exercise testing after traumatic brain injury: submaximal and peak responses. Am J Phys Med Rehabil. 2005;84:492-500.

33. Borg G. Perceived exertion as an indicator of somatic stress. Scand J Rehabil Med. 1970;2:92-8.

34. Ellis MJ, Leddy J, Willer B. Multi-disciplinary management of athletes with post-concussion syndrome: an evolving pathophysiological approach. Front Neurol. 2016;7:136.

35. American College of Sports Medicine. ACSM's guidelines for exercise testing and prescription, 8th ed. Philadelphia: Wolters Kluwer; 2010.

36. Mossberg KA. Reliability of a timed walk test in persons with acquired brain injury. Am J Phys Med Rehabil. 2003;82:385-92.

37. Mossberg KA, Fortini E. Responsiveness and validity of the sixminute walk test in individuals with traumatic brain injury. Phys Ther. 2012;92:726-33.

38. Vitale AE, Jankowski LW, Sullivan SJ. Reliability for a walk/run test to estimate aerobic capacity in a brain-injured population. Brain Inj. 1997;11:67-76.

39. Alali AS, Scales DC, Fowler RA, et al. Tracheostomy timing in traumatic brain injury: a propensity-matched cohort study. J Trauma Acute Care Surg. 2014;76:70-8.

40. Cifu DX, Kaelin DL, Wall BE. Deep venous thrombosis: incidence on admission to a brain injury rehabilitation program. Arch Phys Med Rehabil. 1996;77:1182-5.

41. Kitagawa RS, Van Haren RM, Yokobori S, et al. Management of simultaneous traumatic brain injury and aortic injury. J Neurosurg. 2013;119:324-31.

42. LeRoux P. Haemoglobin management in acute brain injury. Curr Opin Crit Care. 2013;19:83-91.

43. Ravindra VM, Riva-Cambrin J, Sivakumar W, Metzger RR, Bollo RJ. Risk factors for traumatic blunt cerebrovascular injury diagnosed by computed tomography angiography in the pediatric population: a retrospective cohort study. J Neurosurg Pediatr. 2015;15:599-606.

44. Grassi GP, Turci M, Sforza C. Aerobic fitness and somatic growth in adolescents: a cross sectional investigation in a high school context. J Sports Med Phys Fitness. 2006;46:412-8.

45. Archer $\mathrm{T}$. Influence of physical exercise on traumatic brain injury deficits: scaffolding effect. Neurotox Res. 2012;21:418-34.

46. Archer T, Svensson K, Alricsson M. Physical exercise ameliorates deficits induced by traumatic brain injury. Acta Neurol Scand. 2012;125:293-302.

47. Griesbach GS. Exercise after traumatic brain injury: is it a doubleedged sword? PM R. 2011;3:S64-72.

48. Baker JG, Freitas MS, Leddy JJ, Kozlowski KF, Willer BS. Return to full functioning after graded exercise assessment and progressive exercise treatment of postconcussion syndrome. Rehabil Res Pract. 2012; 2012:705309.

49. Clausen M, Pendergast DR, Willer B, Leddy J. Cerebral blood flow during treadmill exercise is a marker of physiological postconcussion syndrome in female athletes. J Head Trauma Rehabil. 2016;31:215-24

50. Mutch WA, Ellis MJ, Ryner LN, et al. Longitudinal brain magnetic resonance imaging $\mathrm{CO} 2$ stress testing in individual adolescent sports-related concussion patients: a pilot study. Front Neurol. 2016;7:107.

51. Chin LM, Chan L, Woolstenhulme JG, Christensen EJ, Shenouda $\mathrm{CN}$, Keyser RE. Improved cardiorespiratory fitness with aerobic exercise training in individuals with traumatic brain injury. J Head Trauma Rehabil. 2015;30:382-90.

52. Mossberg KA, Masel BE, Gilkison CR, Urban RJ. Aerobic capacity and growth hormone deficiency after traumatic brain injury. J Clin Endocrinol Metab. 2008;93:2581-7. 